\title{
ADHD and Stress: The Role of Meditation to Reduce Stress, and Improve Brain Function and Behavior Regulation
}

\author{
Sarina J. Grosswald ${ }^{1}$ and Fred Travis ${ }^{2}$ \\ 1 SJ Grosswald \& Associates \\ ${ }^{2}$ Center for Brain, Consciousness and Cognition \\ United States
}

\section{Introduction}

The number of children worldwide diagnosed with ADHD increases every year. As information about the medical risks associated with ADHD medication is becoming more widely understood, it is not surprising that large numbers of parents are seeking alternative therapies as a response to concerns about the physiological and psychological effects of the drugs.

A growing number of clinicians also support alternative therapies, arguing that an emphasis on medical therapy alone focuses only on control of symptoms, rather than attending to the need for children to develop important behavioral and social skills (Zametkin, \& Ernst, 1999).

While the use of alternative approaches such as yoga, meditation, exercise, special diets, and nutritional supplements for treating children with ADHD is becoming widespread, little is known about the effectiveness of many of these approaches. There is a growing body of research on the beneficial effects of meditation on health risks, psychosocial factors, and on brain development. However there is little published research about the use of meditation for ADHD.

\section{Stress, anxiety and ADHD}

ADHD is associated with impaired executive function, specifically brain circuitry governing behavior (Bush, et al., 2005; Durston, et al., 2004; Zametkin, et al., 1993). Dysfunction of these circuits leads to impulsivity and lack of normal social inhibition. It also leads to impaired working memory, inability to focus attention, and impaired temporal organization.

Stress interferes with executive function and behavior regulation (McEwen, 1998). Stressimpaired executive function is associated with impaired working memory, impaired impulse control, and lack of mental flexibility and coping strategies. Stress also dramatically compromises selective attention and the ability to sustain attention (Lupien, et al., 2005). 
In comparing symptoms of stress and symptoms of ADHD, there is a striking similarity. Recent research sheds light on the relationship between stress and ADHD. Vance, et al., demonstrated dysfunction of the right prefrontal regions of the brain in ADHD children (2007). This region is responsible for developing coping strategies, influencing the ability to handle stress. Chronic acute stress damages the body's ability to return to non-stress levels, leading to chronically elevated levels of cortisol, a biochemical marker of stress. In children with ADHD high cortisol levels impair executive function, self-regulation, and letter knowledge (Blair, Grange, \& Razza, 2005).

Chronic stress can originate not only from emotional causes but can also result from physical origins. Studies of premature birth and birth weight show an association between physical stress and risk of ADHD. Danish researchers found that babies born prematurely had up to $70 \%$ greater risk of ADHD. Similarly, babies born of low birth weight had $50-90 \%$ greater risk of ADHD, depending on the weight at birth (Linnet, Wisborg, Agerbo, Secher, Thomsen, \& Henriksen, 2006).

Early experiences of stress are believed to affect the level of responsiveness of the hypothalamic-pituitary-adrenal axis and the autonomic nervous system. Young children exposed to chronic stress can become conditioned to higher levels of adrenaline. This raises the "set point," making these children more vulnerable to stress, resulting in situations more easily triggering stress responses.

\section{Pharmaceutical treatment}

The United States Centers for Disease Control and Prevention estimates that over $66 \%$ of children diagnosed with ADHD are taking medication (CDC, 2008). The agency states, however, that concern persists regarding the side effects and long-term health outcomes associated with these drugs (CDC, 2005).

Further, the long term effectiveness of pharmaceutical treatment is mixed. The largest study conducted on ADHD treatment was the Multimodal Treatment Study of Children with ADHD, referred to as the MTA, published in 1999, which reported effectiveness of drug treatment (MTA Cooperative Group, 1999). However follow-up studies at three years and eight years, reported no significant differences in symptoms among the children who received the intensive drug treatments and those who did not (Molina, et al. 2009; Jensen, et al. 2007). Additionally, those on the drug regimens had significantly higher rates of delinquency and substance use (Molina, Flory, Hinshaw, Greiner, Arnold, \& Swanson, 2007).

Persistent and negative side effects of the drugs include sleep disturbances, reduced appetite, weight loss, suppressed growth, and mood disorders. The long-term effects are not fully known at this time; however evidence suggests risks of cardiac disorders and sudden death, liver damage, and psychiatric events. The side-effects and long-term health outcomes associated with the drug treatment have potentially important health implications for the millions of children who are currently taking medication for ADHD (CDC, 2005). Consequently, there is a growing interest in alternative treatment options, such as nutritional approaches, meditation, and yoga. 


\section{Meditation}

There are many systems of meditation, which differ widely from one another in their procedures, content, beliefs, and goals. Research has shown that the different techniques have different subjective and objective effects. Meditation types have generally been classified into two categories: techniques of concentration or techniques of contemplation (Shapiro, 1982). Each of these different techniques uses different processes and thus has different effects (Orme-Johnson, \& Walton, 1998; Shear, 2006).

Most recently, Travis and Shear (2010) identified three types of meditation practices, classified according to their EEG signatures and the corresponding cognitive processes. The three classifications are focused attention, open monitoring, and automatic selftranscending.

Techniques of focused attention are concentration techniques, and are associated with voluntary sustained control of attention to keep it focused on the object of meditation, such as an event, image, or sound. The brain activity during concentration meditations is characterized by EEG in the beta-2 $(20-30 \mathrm{~Hz})$ and gamma $(30-50 \mathrm{~Hz})$ frequency bands. Open monitoring or mindfulness-based techniques, involve dispassionate non-evaluative monitoring of ongoing experience. These techniques are characterized by frontal theta (5-8 $\mathrm{Hz})$ EEG, and perhaps occipital gamma $(30-50 \mathrm{~Hz})$ EEG. Automatic self-transcending meditation is defined as effortless transcending of the meditation process itself (Travis \& DuBois, 2004; Travis \& Shear, 2010). EEG activity of an automatic self-transcending technique is associated with alpha-1, characteristic of reduced mental activity and relaxation.

Research has shown improvements in attention and flexibility among a study group that was using various different forms of meditation (Rutschman, 2004), and in ADHD symptoms using Sahaja yoga meditation, a form of contemplative or open monitoring meditation (Harrison, Manocha, \& Rubia, 2004).

The Transcendental Meditation technique falls into the category of automatic selftranscending. Concentration and open monitoring meditations both require some mental effort (i.e., holding attention on its object or maintaining a stance of open monitoring, respectively). The Transcendental Meditation technique is said to automatically lead to the experience of "consciousness itself," awareness without any objects of awareness, a lowstress state called transcendental or pure consciousness (Travis \& Pearson, 2000).

It is described as a simple and effortless, non-religious mental technique that is easy to learn, and does not require the ability to concentrate or control the mind. Regular practice of the technique creates a state referred to as "restful alertness." The term reflects a combination of markedly decreased metabolism, heart rate, respiration rate, and blood flow to the limbs, similar to deep rest or sleep; while at the same time mental alertness is maintained, as measured by EEG (Dillbeck, \& Orme-Johnson, 1987; Jevning, Wallace, \& Beidebach, 1992; Orme-Johnson, 1973; Travis, \& Wallace, 1999; Wallace, 1970).

EEG measurements also show increases in brain coherence both during the practice of the Transcendental Meditation technique and afterwards in activity (Travis and Shear 2010; Dillbeck \& Araas-Vesely, 1986; So \& Orme-Johnson, 2001). The primary areas of brain 
activated during the practice are the frontal and prefrontal executive areas responsible for attention, executive function, emotional stability, and anxiety (Dixon, et. al., 2005; So, 2001; Fergusson, 1993; Gaylord, Orme-Johnson, \& Travis, 1989).

Positive effects of the Transcendental Meditation technique extend to the noradrenergic networks (Jevning, Wallace, \& Beidebach, 1992; Jevning, Wilson,\& Davidson, 1978; MacLean, Walton, Wennenberg, et. al., 1997; Walton, Gelderloos, \& MacRae, 1995). The practice of the technique results in a decrease in the stress hormone cortisol, both during meditation and longitudinally, outside meditation during activity. Practice of the technique increases serotonin availability, improving mood and reducing the activation of the brain centers for fear, anxiety, and anger.

The use of the TM technique for stress reduction in adolescents has resulted in improvement in school behavior, decreases in absenteeism and rule infractions, and reduction in suspensions due to behavior-related problems (Barnes, Bauza, \& Trieber, 2003). Students practicing the TM technique show higher performance on scales of self-actualization (Alexander, Rainforth, \& Gelderloos, 1991), increased emotional regulation, and improved well-being (Rosaen \& Benn, 2006), as well as improved academic performance.

This chapter describes two research studies examining the effects of the Transcendental Meditation technique in reducing stress, improving the symptoms of ADHD, and improving brain coherence and executive function.

\section{Pilot study}

The Transcendental Meditation technique was selected for an exploratory study to evaluate whether regular practice of the technique by children ages 11 to 14 with ADHD would result in improvements in stress, behavioral symptoms, and executive function.

\subsection{Subjects}

The study was conducted at an independent school for children with language-based learning disabilities. Participation in the study was restricted to students with pre-existing diagnoses of ADHD. The cohort was 10 students ages 11-14, nine boys and one girl. All had a diagnosis of ADHD, six with inattentive-type and four with combined-type. Six students had comorbidities including general anxiety disorder, dysthymia, obsessive compulsive disorder, pervasive developmental disorder, sleep disorders, and tics. Eight students were taking stimulants (e.g. Concerta, Ritalin); three of those were also on other medications such as antidepressants (e.g. Zoloft, Welbutrin) and atypical antipsychotics (e.g., Risperdal). By virtue of attending the school, all students had language-based learning disabilities.

\subsection{Measures}

Data collection was divided into two categories to correspond to the primary and secondary hypotheses: 1) measures of stress, anxiety, ADHD symptoms as reported by parent, teacher, and student inventories, 2) measures of executive function as measured by parent and teacher inventories, and by performance tests. Anecdotal information was collected by informal video interviews at pre- and post test times. 


\subsubsection{Stress, anxiety, and ADHD symptoms}

Teachers and parents completed the Achenbach Child Behavior Checklist (CBCL) inventory, which is validated as diagnostic of ADHD based on criteria defined in the Diagnostic and Statistical Manual of Mental Disorders, fourth edition (DSM-IV). The CBCL is one of the most widely-used measures in child psychology, assessing behavior and social competency. It is composed of 112 items, each differentiating clinical from non-clinical children. Summarized in two categories: Syndrome Scales and DSM-Oriented Scales, the CBCL provides eight symptom subscale scores and a Total Problem score.

Students completed the self-administered Achenbach Youth Self-Report (YSR) and the Revised Children's Manifest Anxiety Scale (RCMAS) to assess overall behavioral and emotional functioning. The YSR is a companion to the CBCL, providing parallel measures from the teachers, parents, and students. Like the CBCL the YSR has 112 items measuring eight subscale symptoms categorized under Syndrome Scales and DSM-Oriented Scales, and a Total Problem score. The RCMAS is a 37-item self-report instrument assessing the level and nature of anxiety in children and adolescents.

\subsubsection{Executive function}

Teachers and parents completed the Behavior Rating Inventory of Executive Function (BRIEF). The BRIEF consists of 86 items divided into eight subscales. These scales form two broader indices: Behavioral Regulation and Metacognition. These two indices are combined to create an overall Global Executive Composite score. The BRIEF assesses behavior regulation and executive functioning.

Four performance tests were used to measure different aspects of executive function. The Cognitive Assessment System (CAS) Expressive Attention, Delis-Kaplan Executive Function System (D-KEFS) Verbal Fluency test, Tower of London (TOL), and Connor's CPT II.

The CAS Expressive Attention subtest is a color-word interference test. It measures higher level complex attention, and ability to inhibit. Names of colors are presented in ink colors of either the name of the color or a different color. When the color of ink is different from the color name the task requires attention, inhibiting the reflexive response, and cognitive processing (switching) to say the correct color.

The D-KEFS Verbal Fluency subtest measures the ability to generate words fluently, generate words in specific categories, and shift attention by switching from one category to another. The student is asked to list as many words as possible starting with a certain letter, to name as many items in a category, and to name items switching from one category to another.

The TOL measures higher order problem-solving, and is used to evaluate difficulties in executive function. Subjects are shown a configuration of colored balls stacked on pegs. The subject executes a sequence of moves that transforms his or her board to match the displayed configuration with the balls arranged on the designated pegs.

The Connors' Continuous Performance Test (CPT) II is a computerized test that measures sustained attention. The subject is presented stimuli on a computer screen (e.g., a letter or asterisk) and is asked to respond by pressing a button only when detecting a specified letter after seeing another specified letter. 


\subsection{Procedure}

Six weeks before the start of the intervention, two classroom teachers and two administrators at the school were instructed in the Transcendental Meditation technique, in the same way the students would be (see below). The instruction in Transcendental Meditation is standardized and all practitioners around the world are instructed in the identical way, thus assuring consistency in instruction and in practice of the technique.

Following completion of baseline assessments, students were provided the standard 7-Step course of instruction in the Transcendental Meditation technique (see 5.4 below). All 10 children in the group were able to learn the TM technique, and practice it successively as evidenced during the morning and afternoon TM sessions and by responses to course assessment questionnaires.

Over the 3-month study period, subjects participated in customary follow-up checks of correct meditation, which is standard with the instruction of the technique. Students meditated at school in a group for 10 minutes twice each day, once in the morning and once in the afternoon. The classroom teachers who had also learned TM led the students in twice daily meditation sessions at the school, telling students when to begin and end meditation, and timing the meditation. The Certified TM teachers monitored the group meditation two or three times a month to assure correct group meditation.

Parents were encouraged to have students continue regular meditation at home on weekends and holidays. Home compliance was not rigorously monitored.

\subsection{Intervention: The Transcendental Meditation technique}

The Transcendental Meditation technique is a mental technique practiced for 10-20 minutes twice each day, sitting in a chair with eyes closed. The technique is taught by certified Transcendental Meditation teachers. The 7-Step course of instruction involves two informational lectures (Steps 1 and 2), a brief interview with the TM instructor (Step 3), individual personal instruction (Step 4), which is followed by three days of verification of practice and additional information (Steps 5-7). The interview is about 10 minutes, while the remaining steps are approximately one hour each day. Each step can be conducted in a group except Step 4, which is conducted individually, one-on-one. Periodic meetings with the student assures correct practice and reinforces regularity of the practice.

During the course of instruction, the student learns how to let the mind move from active focused levels of thinking to silent, expanded levels of wakefulness at the source of thought, without concentration or effort (Travis, 2001).

After the personal instruction, students in the study meditated in a group at the beginning of the first period in the morning and the beginning of the last period in the afternoon. Meditation sessions were led by a school faculty member also instructed in the TM technique. A certified TM teacher periodically monitored group meditations, and met with students individually as needed to assure correct practice as described above. Three months after instruction, post testing was administered.

\subsection{Results}

Variables were grouped into two conceptual categories to correspond to the hypotheses. One grouping, stress, anxiety, and ADHD symptoms, included the associated variables from 
the YSR, RCMAS, and CBCL. The second grouping, executive functioning, included the responses from teachers on the BRIEF, and the data from the performance tests. Analysis was conducted on measures for which there was complete data $(\mathrm{N}=10)$.

Parent inventories and CPT scores were not included in the analysis because fifty percent of the parent post test inventories were not returned, and thirty percent of students had already left school for summer break at the time of CPT post testing.

Raw scores were used for all analyses except performance tests, which were converted to standard scores using the tables provided in the test manuals. Repeated measure MANOVAs were used to test for significant pre-posttest differences.

\subsection{Stress, anxiety, and ADHD symptoms}

From the YSR, the variables selected for analysis were Anxious/Depressed, Withdrawn/ Depressed, Affective Problems, Anxiety Problems, Attention Problems, ADHD Problems, and Total Problems (Table 1). Added to these variables was the single result of the RCMAS. The analysis yielded significant improvement of symptoms from pretest to post test $\mathrm{F}(1,9)=4.7, \mathrm{p}=.0285$.

The same measures analyzed from the YSR were selected for analysis of the teacher reported CBCL. Teacher results corroborated student reported significant reductions in symptoms, $\mathrm{F}(1,9)=6.5, \mathrm{p}=.0155$.

\begin{tabular}{|c|c|c|c|c|c|c|c|c|c|c|}
\hline \multicolumn{6}{|c|}{ Student } & \multicolumn{5}{|c|}{ Teacher } \\
\hline & \multicolumn{2}{|c|}{ Pretest } & \multicolumn{2}{|c|}{ Post Test } & & \multicolumn{2}{|c|}{ Pretest } & \multicolumn{2}{|c|}{ Post Test } & \\
\hline Symptom & Mean & SD & Mean & SD & ES & Mean & SD & Mean & SD & ES \\
\hline $\begin{array}{l}\text { Anxious/ } \\
\text { Depressed }\end{array}$ & 5.7 & 3.6 & $2.7^{*}$ & 3.7 & .8 & 10.2 & 6.4 & $5.6^{*}$ & 3.6 & .7 \\
\hline $\begin{array}{l}\text { Withdrawn/ } \\
\text { Depressed }\end{array}$ & 4.8 & 2.7 & $3.9^{* *}$ & 3.0 & .3 & 4.3 & 3.8 & 3.6 & 4.0 & .2 \\
\hline $\begin{array}{l}\text { Affective } \\
\text { Problems }\end{array}$ & 5.8 & 3.4 & $4.1^{*}$ & 2.5 & .5 & 5.0 & 3.7 & 3.6 & 3.6 & .4 \\
\hline $\begin{array}{l}\text { Anxiety } \\
\text { Problems }\end{array}$ & 3.2 & 2.0 & $1.6^{* *}$ & 1.9 & .8 & 3.7 & 3.5 & 2.1 & 2.4 & .5 \\
\hline $\begin{array}{l}\text { Attention } \\
\text { Problems }\end{array}$ & 7.0 & 4.0 & $5.2^{*}$ & 3.5 & .5 & 23.6 & 10.5 & 22 & 11.0 & .2 \\
\hline $\begin{array}{l}\text { ADHD } \\
\text { Problems }\end{array}$ & 5.4 & 2.9 & 4.3 & 2.7 & .4 & 12.4 & 5.7 & 11.7 & 5.7 & .3 \\
\hline $\begin{array}{l}\text { Total } \\
\text { Problems }\end{array}$ & 52.5 & 25.6 & $40^{*}$ & 27.4 & .5 & 63.1 & 24.8 & $56^{*}$ & 31.2 & .3 \\
\hline
\end{tabular}

${ }^{*} \mathrm{p} \leq .05 .{ }^{* *} \mathrm{p}<.005 \mathrm{ES}=$ Effect Size

Table 1. Achenbach Youth Self Report, Stress, Anxiety, and ADHD Symptoms

\subsection{Executive function}

The BRIEF includes 3 composite measures: Behavioral Regulation Index, Metacognition Index, and General Executive Composite. The Global Executive Composite is composed of 
the Behavioral Regulation Index and the Metacognition Index. A repeated measures MANOVA of the General Executive Composite indicated significant improvement in executive function from pretest to post test, $F(1,9)=5.5, p=.022$. Repeated measures MANOVA on the scales comprising the two indices also were statistically significant: Behavioral Regulation Index (Inhibit, Shift, and Emotional Control), F(1,9) = 23.7, p <.00001; and Metcognition Index (Initiate, Working Memory, Planning, Organize Material, and Monitoring), $F(1,9)=13.7, p=.0025$. Table 2 presents the pre- and post test means and standard deviations for the individual scales associated with each index.

The Tower of London was omitted from analysis because the assessment has been found to be less consistent than other measures in distinguishing specific effects associated with ADHD from those related to learning disorders (Sergeant, Geurts, \& Oosterlaan, 2002).

\begin{tabular}{|l|c|c|c|c|}
\hline & \multicolumn{2}{|c|}{ Pre-Test } & \multicolumn{2}{c|}{ Post Test } \\
\hline \multicolumn{1}{|c|}{ Scale } & Mean & SD & Mean & SD \\
\hline $\begin{array}{l}\text { Behavioral Regulation } \\
\text { Index (BRI) }\end{array}$ & 54.1 & 16.9 & $46.4^{*}$ & 13.2 \\
\hline Inhibit & 19.0 & 6.9 & $17.1^{*}$ & 6.5 \\
\hline Shift & 18.5 & 5.3 & 15.5 & 3.9 \\
\hline Emotional Control & 16.6 & 6.7 & $13.8^{*}$ & 4.3 \\
\hline Metacognition Index (MI) & 94.8 & 32.1 & 85.3 & 23.2 \\
\hline Initiate & 15.1 & 3.7 & $13.2^{*}$ & 3.2 \\
\hline Working Memory & 22.8 & 4.2 & $20.1^{*}$ & 5.3 \\
\hline Plan/Organize & 21.8 & 4.4 & 20.6 & 5.5 \\
\hline Organization of Materials & 14.6 & 4.9 & 13.2 & 5.0 \\
\hline Monitor & 20.4 & 5.9 & $18.2^{*}$ & 4.5 \\
\hline $\begin{array}{l}\text { General Executive } \\
\text { Composite (GEC) }\end{array}$ & 151.6 & 37.7 & $131.7^{*}$ & 33.1 \\
\hline
\end{tabular}

${ }^{*} \mathrm{p} \leq .05$

Table 2. Teacher Behavior Rating Inventory of Executive Function (BRIEF)

The performance measures analyzed were the CAS and the D-KEFS (Table 3). The CAS scores of Expressive Attention and Accuracy Ratio were combined with the D-KEFS scores for Category Fluency and Category Switching. A repeated measures MANOVA yielded a significant improvement in scores on these performance measures from pre to posttest, $\mathrm{F}(1,9)=5.0, \mathrm{p}=.026$.

\begin{tabular}{lccccc}
\hline \multirow{2}{*}{ Measure } & \multicolumn{2}{c}{ Pre-Test } & & Post Test \\
\cline { 2 - 3 } & Mean & SD & Mean & SD \\
\hline CAS Expressive Attention & 36.10 & 10.63 & & $44.70^{*}$ & \\
CAS Accuracy & 37.70 & 2.21 & & $39.40^{*}$ & \\
D-KEFS Category Fluency & 25.10 & 7.83 & 28.70 & \\
D-KEFS Category Switching & 8.30 & 3.19 & 9.60 & 7.61 \\
\hline
\end{tabular}

${ }^{*} \mathrm{p} \leq .05$.

Table 3. Performance Measures 


\section{Randomized controlled trial of brain function}

To further understand the effects of the Transcendental Meditation technique on children with ADHD, a second study explored improvements in brain coherence and brain development. The purpose was to provide insight into the underlying mechanisms of observed changes. A randomized controlled trial examined the EEG coherence, theta/beta ratio, and executive function.

EEG studies report decreased activation in ADHD populations in parietal areas of the brain that weave sensory input into concrete perception (Silk et al., 2005), higher density and amplitude of theta activity (di Michele, Prichep, John, \& Chabot, 2005; Janzen, Graap, Stephanson, Marshall, \& Fitzsimmons, 1995), and lower density and amplitude of alpha and beta activity (Barry, Clarke, \& Johnstone, 2003). Theta/beta power ratios are highly correlated with severity of ADHD symptoms (Monastra, Lubar, \& Linden, 2001; Monastra et al., 1999).

During memory tasks, theta EEG is generated in the hippocampus and is thought to block out irrelevant stimuli during memory processing. In ADHD subjects, greater theta activity may block out relevant as well as irrelevant information.

Another brain marker of ADHD is EEG coherence, a measure that reflects the number and strength of connections between different brain areas (Thatcher, Walker, \& Giudice, 1987). In children diagnosed with ADHD, coherence in all frequencies is reported lower (Barry, Clarke, McCarthy, \& Selikowitz, 2007, 2009). Alpha coherence is thought to play an important role in attention and consciousness.

\subsection{Subjects}

As in the previous study, the subjects were students at an independent school for children with language-based learning differences. Eighteen students were stratified by age, and randomly assigned to learn TM immediately (TM Group: 6 boys, 3 girls, average age $12.9 \pm$ 1.3) or learn TM in three months (Delayed-Start Group: 7 boys, 2 girls, average age $13.0 \pm$ 1.6). Co-morbidities included General Anxiety Disorder (3 subjects), Obsessive Compulsive Disorder (1 subject), and Autism (3 subjects). In each group, five of the nine subjects were on ADHD medication.

\subsection{Measures}

\subsubsection{Executive function}

The Delis-Kaplan Executive Function System (D-KEFS) Verbal Fluency and the Tower of London were used to replicate the previous study. Inventories included the BRIEF, the Achenbach Child Behavior Checklist, and the Spielberger State Trait Anxiety Scale.

EEG was recorded during a computer-administered paired choice reaction-time task to calculate theta/beta ratios and patterns of EEG coherence. The task began with a display on a computer screen of a one- or two-digit number, followed by a blank screen, then another one- or two-digit number. Subjects were asked to press a left- or right-hand button to indicate which number was larger in value. 


\subsection{Results}

The primary analysis tested differences from baseline to the 3-month posttest. The Transcendental Meditation group practiced the TM technique for three months along with the curriculum designed for children with language-based learning disabilities; the delayedstart comparison group received only the curriculum at the school. In this analysis two repeated measures MANOVAs were conducted - psychological and performance variables in one, and coherence in the other-and an ANCOVA of theta/beta ratio differences, covarying for pretest scores.

A secondary analysis of the delayed-start group compared differences from baseline to the 3-month posttest, when these subjects were not yet meditating, to differences from the 3month to the 6-month posttest, when these subjects were meditating.

\subsubsection{Theta/beta ratios}

The ANCOVA of theta/beta differences, covarying for pretest scores yielded significant decreases in theta/beta ratios in the $\mathrm{TM}$ group $(\mathrm{F}(1,17)=4.7, \mathrm{p}=.05)$. The average theta/beta ratio seen in normal populations is 3 . At pretest, both groups were well above average $(\mathrm{TM}=9$, delayed-start $=10.2)$. At the 3 -month post test, theta/beta ratios increased in the delayed-start (11.9) group, while the TM subjects moved closer to normal values (7.6). At the 6-month post test, after both groups were practicing the TM technique, theta/beta ratios decreased in both groups (TM=4.9, delayed-start=7.6).

For the delayed start group, theta/beta ratios also significantly decreased from the 3-month to 6-month posttest $(-4$. 3) compared to baseline to 3-month posttest $(1.3)(F(1,8)=5.1, p=$ $.053)$, representing the results of three months practice of the technique.

\subsubsection{Coherence maps}

Coherence maps during pretest, 3-month, and 6-month posttests were averaged within each group and subtracted: coherence at 3-month posttest minus coherence during pretest for the delayed-start and TM group who had been meditating for 3-months; and 6-month posttest minus 3-month posttest in the delayed-start group after they had been meditating for 3months. These coherence difference maps present coherence in theta $(5.0-7.5 \mathrm{~Hz})$, alpha (8.0$12 \mathrm{~Hz})$, beta1 $(13-20 \mathrm{~Hz})$, and gamma bands $(20.5-50 \mathrm{~Hz})$.

Coherence maps (Figure 1) show few sensors with higher coherence in the delayed-start group at the 3-month posttest compared to their pretest values (top row). In contrast, there were many frontal and parietal areas with higher coherence in the TM group at 3-month posttest compared to pretest values (middle row); and there were many frontal and parietal areas with higher coherence in the delayed-start group at the 6-month posttest compared to the 3-month posttest values (bottom row).

\subsubsection{Executive function}

The Delis-Kaplan Executive Function System (D-KEFS) Verbal Fluency and the Tower of London were used to replicate the previous study. Inventories included the BRIEF, the Achenbach Child Behavior Checklist, and the Spielberger State Trait Anxiety Scale. However not enough inventories were returned to provide sufficient complete data for analysis. 
Control Group: Coherence during 3-mon Posttest - Coherence during Pretest

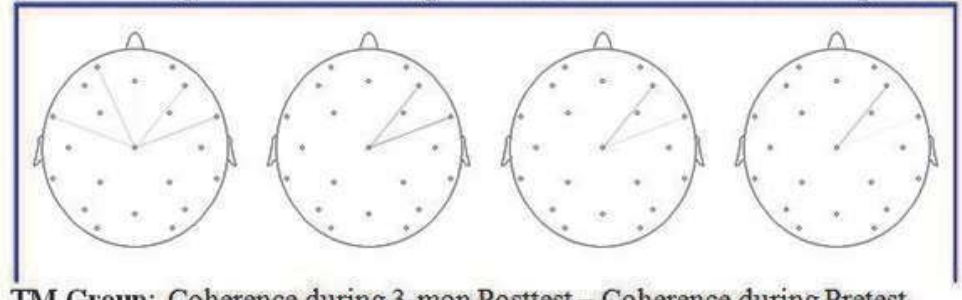

TM Group: Coherence during 3-mon Posttest - Coherence during Pretest

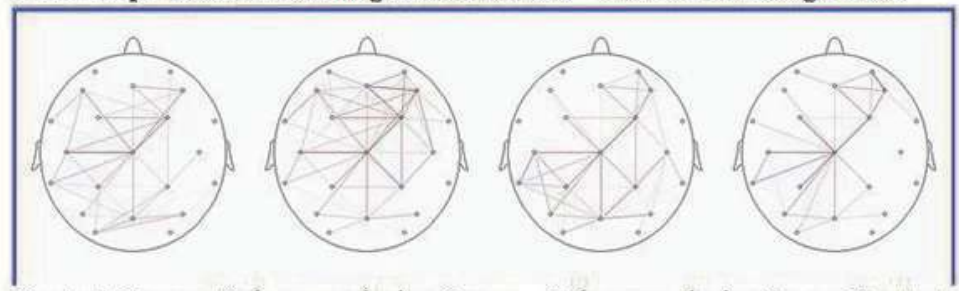

Control Group: Coherence during 6-mon-Coherence during 3-mon Posttest

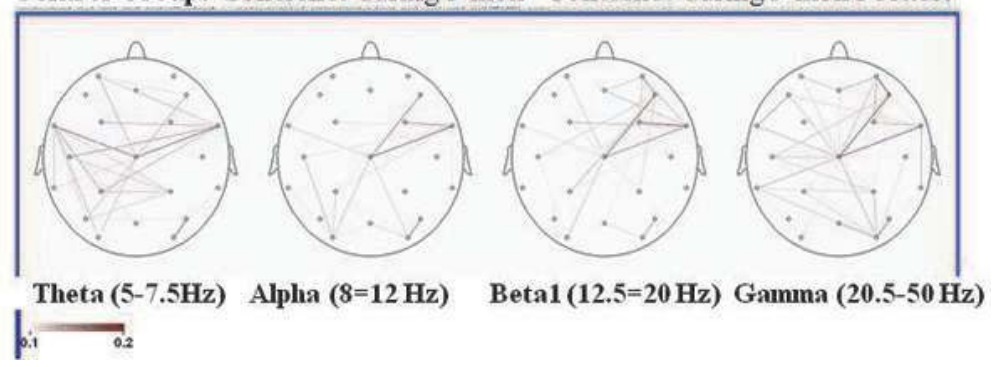

Three coherence-difference maps are presented in this figure. In the top row is coherence during the 3month posttest minus baseline coherence for the delayed-start subjects. The middle row is coherence during the 3-month posttest minus baseline coherence for the TM subjects. The bottom row is coherence during the 6-month posttest minus 3-month posttest for the delayed-start subjects, who had been meditating over this time.

Fig. 1. Coherence maps

\subsubsection{Tower of London}

There were no significant differences between groups from pretest to post test for the Tower of London. There appears to have been significant learning effects in subjects in both groups on this test. As mentioned above, The Tower of London has been found to be less consistent than other measures in distinguishing specific effects associated with ADHD from those related to learning disorders. Consequently this may not be a useful measurement for a population that also has established learning disorders, as was the case in these studies.

\subsubsection{D-KEFS verbal fluency}

There were significant increases from pretest to 3-month posttest in Letter Fluency for the TM group $(\mathrm{F}(1,15)=7.7, \mathrm{p}=.017)$, and no significant group differences on other components of the Verbal fluency test. 
There were also significant increases in D-KEFS in the delayed-start group after they learned TM compared to the time from baseline to the 3-month posttest $(F(1,8)=7.8, p=0.024)$.

\section{Discussion}

Stress and anxiety can overwhelm and lessen the effectiveness of the individual. Anxiousness contributes to poor impulse control, inability to sustain attention, impaired working memory, and lack of cognitive flexibility. This raises the question as to whether, in some cases, it is the symptoms of stress and anxiety that are being diagnosed as ADHD. Whether these problems are a result of ADHD or are the cause of ADHD-like symptoms, these studies suggest that reducing stress and anxiety by the Transcendental Meditation technique can potentially reduce ADHD symptoms and improve executive function.

Compared to other meditation techniques, the Transcendental Meditation technique may be particularly suited to children with ADHD. It is easy to learn and is learned in less than an hour. The technique does not involve controlling the mind; and once learned requires no other time investment than the 10-15 minute sessions twice a day. Yet changes in the brain are seen within a short time.

The Transcendental Meditation technique can be done anywhere one can sit and close the eyes. Therefore it is portable, and a personal means of self-regulation for ADHD children. To maximize the benefits, the recommended routine is one meditation session in the morning and one in the late afternoon, every day. Incorporating the TM program in a school setting, as was used for these studies, provides an excellent means of maintaining regularity, benefiting not only the students but also the school. Teachers' anecdotal comments revealed that teachers were able to teacher more; and the students were able to learn more because they were less stressed and anxious.

With recent research showing reduced ability to cope with stress and slower brain development in ADHD children, a technique that can positively affect both of these factors can be a valuable resource for treatment of ADHD. The technique does not conflict with other cognitive or behavioral approaches, or with medication. With less stress and anxiety, the child may be more responsive to other interventions, potentially increasing their effectiveness.

Both studies were small, therefore we cannot infer strong cause and effect relations between TM practice and reduction in ADHD symptoms. However, the first study included a number of objective performance tests of attention and executive function to support selfreport inventories that are commonly used to diagnosis ADHD. This allowed for withinstudy corroboration of results. The second study provided a strong study design of a randomized controlled trial.

Both the psychosocial improvements and improved brain function seen in these studies are consistent with previous research on the Transcendental Meditation technique. Psychosocial research shows reduced anxiety, increased emotional regulation, and improved social behavior in non-ADHD students. Studies of the effect of the TM technique on executive function show increased frontal brain coherence, associated with more effective executive functioning, improved attention, greater emotional stability, and decreased anxiety. 
These results suggest that further research is warranted to assess the impact of Transcendental Meditation practice as a potential treatment option for ADHD, either alone or as adjunct treatment. It would be valuable to replicate the results with larger groups, and further study improvements in brain coherence and brain development to gain insight into the underlying mechanisms of observed changes.

\section{Conclusions}

The initial pilot study represents the first systematic study of the effects of the Transcendental Meditation technique on the symptomatology of ADHD. The results indicate that Transcendental Meditation practice 1) can be learned and successfully practiced by children with ADHD, 2) has the potential to reduce stress, anxiety, and stress related ADHD symptoms within three months, and 3) can result in improvements in executive function.

In the random assignment study, three months practice of the TM technique resulted in 1) significant decreases in theta/beta ratios, 2) significant increases in theta coherence, and trends for increases in alpha and beta coherence during tasks, and 3) significant increases in Letter Fluency. The single-group within analysis yielded similar decreases in theta/beta ratios and increases in Letter Fluency after the delayed-start group learned TM.

\section{Acknowledgements}

The authors would like to thank their co-investigator William Stixrud, Ph.D., Department of Psychiatry, George Washington University School of Medicine and Health Sciences.

\section{References}

Alexander, C.N., Rainforth, M.V., Gelderloos, P. (1991), Transcendental Meditation, selfactualization, and psychological health: a conceptual overview and statistical metaanalysis, Journal of Social Behavior and Personality, 6(5), 189-247.

Barnes, V. A., Bauza, L. B., \& Trieber. F, A. (2003). Impact of stress reduction on negative school behavior in adolescents. Health Quality of Life Outcomes, 1(10). Retrieved from http://www.hqlo.com/content/1/1/10.

Barry, R. J., Clarke, A. R., \& Johnstone, S. J. (2003). A review of electrophysiology in attention-deficit/hyperactivity disorder: I. Qualitative and quantitative electroencephalography. Clinical Neurophysiology, 114(2), 171-183.

Barry, R. J., Clarke, A. R., McCarthy, R., \& Selikowitz, M. (2007). EEG coherence in children with attention-deficit/hyperactivity disorder and comorbid oppositional defiant disorder. Clinical Neurophysiology, 118(2), 356-362.

Blair C., Grange G. R., \& Razza, R. P. (2005). Cortisol reactivity is positively related to executive function in preschool children attending head start child development. Child Development, 76(3), 554-567.

Bush, G., Valera, E. M., \& Seidman, L. J. (2005). Functional neuroimaging of attentiondeficit/hyperactivity disorder: a review and suggested future directions. Biological Psychiatry, 7(11), 1273-1284. 
Centers for Disease Control and Prevention. (2008, July). Diagnosed Attention Deficit Hyperactivity Disorder and Learning Disability: United States, 2004-2006. Vital and Health Statistics, 10 (237).

Centers for Disease Control and Prevention. (2005). Morbidity and Mortality Weekly Report, 54, 842-847.

Dillbeck, M.C., \& Araas-Vesely, S. (1986). Participation in the Transcendental Meditation program and frontal EEG coherence during concept learning. International Journal of Neuroscience, 29, 45-55.

Dillbeck, M. C., \& Orme-Johnson, D. W. (1987). Physiological differences between Transcendental Meditation and rest. American Psychologist, 42, 879-881.

di Michele, F., Prichep, L., John, E. R., \& Chabot, R. J. (2005). The neurophysiology of attention-deficit/hyperactivity disorder. International Journal of Psychophysiology, 58(1), 81-93.

Durston S., Hulshoff Pol H. E., Schnack, H. G., Buitelaar, J. K., Steenhuis, M, P., Minderaa, R. B., et. al. (2004). Magnetic resonance imaging of boys with attentiondeficit/hyperactivity disorder and their unaffected siblings. Journal of the American Academy of Child and Adolescent Psychiatry, 43(3), 332-340.

Fergusson, L. C. (1993). Field independence, Transcendental Meditation and achievement in college art: a reexamination. Perceptual and Motor Skills, 77, 1104-1106.

Gaylord, C., Orme-Johnson, D., \& Travis, F. (1989). The effects of the transcendental meditation technique and progressive muscle relaxation on EEG coherence, stress reactivity, and mental health in black adults. International Journal of Neuroscience, 46(1-2), 77-86.

Harrison, L. J., Ramesh, M., \& Rubia, K. (2004). Sahaja yoga meditation as a family treatment programme for children with attention deficit-hyperactivity disorder. Clinical Child Psychology and Psychiatry, 9(4), 479-497.

Janzen, T., Graap, K., Stephanson, S., Marshall, W., \& Fitzsimmons, G. (1995). Differences in baseline EEG measures for ADD and normally achieving preadolescent males. Biofeedback Self Regul, 20(1), 65-82.

Jensen, P. S., Arnold, E., Swanson, J. M., Vitiello, B., Abikoff, H. B., Greenhill, L. L., et al. (2007). 3-Year Follow-up of the NIMH MTA Study. Journal of the American Academy of Child and Adolescent Psychiatry, 46 (8), 989-1002.

Jevning, R., Wallace, R., \& Beidebach, M. (1992). The physiology of meditation: a review. A wakeful hypometabolic integrated response. Neuroscience and Biobehavioral Reviews, $16,415-424$.

Jevning, R., Wilson, A. F., \& Davidson, J. M. (1978). Adrenocortical activity during meditation. Hormones and Behavior, 40, 603-606.

Linnet, K. M., Wisborg, K., Agerbo, E., Secher, N. J., Thomsen, P. H., \& Henriksen, T. B. (2006). Gestational age, birth weight, and the risk of hyperkinetic disorder. Archives of Disease in Childhood, 91, 655-660.

Lupien, S. J., Fiocco, A., Wan, N., Maheu, F., Lord, C., Schramek, T., et al. (2005). Stress hormones and human memory function across the lifespan. Psychoneuroendocrinology, 30 (3), 225-242.

MacLean, C. R. K., Walton, K. G., Wennenberg, S. R., Levitsky, D. K., Mandarino, J. P., Waziria, R., et al. (1997). Effects of the Transcendental Meditation program on 
adaptive mechanisms: changes in hormone levels and responses to stress after 4 months of practice. Psychoneuroendocrinology, 22(4), 277-295

McEwen, B. S. (1998). Protective and damaging effects of stress mediators. New England Journal of Medicine, 338(3), 171-179.

Molina, B. S., Hinshaw, S. P., Swanson, J. M., Arnold, E. L., Epstein, J. N., Hoza, B., et al. (2009). The MTA at 8 years: prospective follow-up of children treated for combined-type ADHD in a mulitsite study. Journal of the American Academy of Child and Adolescent Psyciatry, 48 (5), 484-500.

Molina, B., Flory, K., Hinshaw, S., Greiner, A., Arnold, L., \& Swanson, J. (2007). Delinquent behavior and emerging substance use in the MTA at 36 months: Prevalence, course, and treatment effects. Journal of the American Academy of Child and Adolescent Psychiatry , 46 (8), 1028-1040.

Monastra, V. J., Lubar, J. F., \& Linden, M. (2001). The development of a quantitative electroencephalographic scanning process for attention deficit-hyperactivity disorder: reliability and validity studies. Neuropsychology, 15(1), 136-144.

Monastra, V. J., Lubar, J. F., Linden, M., VanDeusen, P., Green, G., Wing, W., et al. (1999). Assessing attention deficit hyperactivity disorder via quantitative electroencephalography: an initial validation study. Neuropsychology, 13(3), 424-433.

MTA Cooperative Group. (1999). A 14-month randomized clinical trial of treatment strategies for attention-deficit/hyperactivity disorder. The MTA Coorperative Group. Modality Treatment Study of Children with ADHD. Archives of General Psychiatry , 56 (12), 1073-86.

Orme-Johnson, D.W. (1973). Autonomic stability and Transcendental Meditation. Psychosomatic Medicine, 35, 341-349.

Orme-Johnson D., \& Walton, K. G. (1998). All approaches to preventing or reversing effects of stress are not the same. American Journal of Health Promotion, 12(5), 297-299.

Rosaen, C, \&. Benn, R. (2006). The experience of Transcendental Meditation in middle school students: a qualitative report. Explore, 2(5), 422-425.

Rutschman, J. R. (2004). Effects of techniques of receptive meditation and relaxation on attentional processing. Canadian Undergraduate Journal of Cognitive Science, 6-16.

Sergeant, J. A., Geurts, H., \& Oosterlaan, J. (2002). How specific is a deficit of executive function for attention deficit/hyperactivity disorder? Behavioral Brain Research 130, 3-28.

Shapiro, D. H. (1982). Clinical and physiological comparison of meditation and other selfcontrol strategies. American Journal of Psychiatry, 139, 267-274.

Shear, J. (2006). The Experience of Meditation: Experts Introduce the Major Traditions. Paragon House, St. Paul, MN.

Silk, T., Vance, A., Rinehart, N., Egan, G., O'Boyle, M., Bradshaw, J. L., et al. (2005). Frontoparietal activation in attention-deficit hyperactivity disorder, combined type: functional magnetic resonance imaging study. British Journal of Psychiatry, 187, 282283.

So, K. T., \& Orme-Johnson, D.W. (2001). Three randomized experiments on the longitudinal effects of the Transcendental Meditation technique on cognition. Intelligence, 29, 419-440.

Thatcher, R. W., Walker, R. A., \& Giudice, S. (1987). Human cerebral hemispheres develop at different rates and ages. Science, 236(4805), 1110-1113. 
Travis, F., \& Shear, J. (2010). Focused attention, open monitoring and automatic selftranscending:Categories to organize meditations from Vedic, Buddhist and Chinese. Consciousness and Cognition. In press. Retrieved from doi:10.1016/j.concog.2010.01.007

Travis, F. T., \& DuBois, D. (2004). Psychological and physiological charactieristics of a proposed object-referral/self-referral continuum of self-awareness. Consciousness and Cognition, 12 (2), 401-420.

Travis, F. (2001). Transcendental Meditation Technique. In E. W. Craighead \& C. B. Nemeroff (Eds.), Corsini Encyclopedia of Psychology and Neuroscience (pp. 17051706). New York: John Wiley and Sons.

Tavis, F. T., \& Pearson, C. (2000). Pure consciousness: distinct phenomenological and physiological correlates of "consciousness itself". International Journal of Neuroscience, 100 (1-4), 77-89.

Travis, F., \& Wallace, R. K. (1999). Autonomic and EEG patterns during eyes-closed rest and Transcendental Meditation (TM) practice: A basis for a neural model of TM practice. Consciousness and Cognition, 8, 302-318.

Vance, A., Silk, T. J., Casey, M., Rinehart, N. J., Bradshaw, J. L., Bellgrove, M. A., et al. (2007). Right parietal dysfunction in childen with atention deficit hyperactivity disorder, combined type: Afunctional MRI study. Molecular Psychiatry , 12 (9), 826-832.

Wallace, R. K. (1970). Physiological effects of Transcendental Meditation. Science, 167, 17511754.

Walton, K. G., Pugh, B. S., Gelderloos, P., \& MacRae, P. (1995). Stress reduction and preventing hypertension: Preliminary support for a psychoneuroendocrine mechanism. The Journal of Alternative and Complementary Medicine, 1(3), 263-283.

Zametkin, A. J., \& Ernst, M. (1999). Problems in the management of attention-deficithyperactivity disorder. New England Journal of Medicine, 7, 340(1), 40-46.

Zametkin, A.J., Liebenauer, L. L., Fitzgerald, G. A., King, A. C., Minkunas, D. V., Herscovitch, P., et. al.(1993). Brain metabolism in teenagers with attention-deficit hyperactivity disorder. Archives of General Psychiatry, 50(5), 333-340. 




\author{
Current Directions in ADHD and Its Treatment \\ Edited by Dr. Jill M. Norvilitis
}

ISBN 978-953-307-868-7

Hard cover, 302 pages

Publisher InTech

Published online 15, February, 2012

Published in print edition February, 2012

The treatment of Attention Deficit Hyperactivity Disorder is a matter of ongoing research and debate, with considerable data supporting both psychopharmacological and behavioral approaches. Researchers continue to search for new interventions to be used in conjunction with or in place of the more traditional approaches. These interventions run the gamut from social skills training to cognitive behavioral interventions to meditation to neuropsychologically-based techniques. The goal of this volume is to explore the state-of-the-art in considerations in the treatment of ADHD around the world. This broad survey covers issues related to comorbidity that affect the treatment choices that are made, the effects of psychopharmacology, and nonmedication treatments, with a special section devoted to the controversial new treatment, neurofeedback. There is something in this volume for everyone interested in the treatment of ADHD, from students examining the topic for the first time to researchers and practitioners looking for inspiration for new research questions or potential interventions.

\title{
How to reference
}

In order to correctly reference this scholarly work, feel free to copy and paste the following:

Sarina J. Grosswald and Fred Travis (2012). ADHD and Stress: The Role of Meditation to Reduce Stress, and Improve Brain Function and Behavior Regulation, Current Directions in ADHD and Its Treatment, Dr. Jill M. Norvilitis (Ed.), ISBN: 978-953-307-868-7, InTech, Available from: http://www.intechopen.com/books/currentdirections-in-adhd-and-its-treatment/adhd-and-stress-the-role-of-meditation-to-reduce-stress-and-improvebrain-function-and-behavior-regu

\section{INTECH}

open science | open minds

\section{InTech Europe}

University Campus STeP Ri

Slavka Krautzeka 83/A

51000 Rijeka, Croatia

Phone: +385 (51) 770447

Fax: +385 (51) 686166

www.intechopen.com

\section{InTech China}

Unit 405, Office Block, Hotel Equatorial Shanghai

No.65, Yan An Road (West), Shanghai, 200040, China 中国上海市延安西路65号上海国际贵都大饭店办公楼405单元

Phone: +86-21-62489820

Fax: +86-21-62489821 
(C) 2012 The Author(s). Licensee IntechOpen. This is an open access article distributed under the terms of the Creative Commons Attribution 3.0 License, which permits unrestricted use, distribution, and reproduction in any medium, provided the original work is properly cited. 